\title{
Study on the Preparation Technology of $\mathrm{SiN}_{x}$ Thin Film by PECVD
}

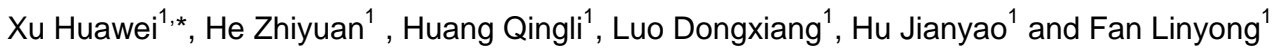 \\ ${ }^{1}$ The Fifth Research Institute of MIIT, Quality Inspection and Testing Center, Dongguan Zhuang Road 110, Guangzhou, China
}

\begin{abstract}
To prepare $\mathrm{SiN}_{\mathrm{x}}$ thin film with good compactness, fast deposition rate and stable performance, plasma-enhanced chemical vapour deposition (PECVD) is adopted to study the influences of different technological parameters on the properties of $\operatorname{SiN}_{\mathrm{x}}$ thin film. The experimental results indicate that $\mathrm{SiH}_{4}$ and $\mathrm{NH}_{3}$ flow rate, temperature, radio-frequency power, pressure and other technological parameters all have influences on the properties of $\mathrm{SiN}_{\mathrm{x}}$ thin film. Among them, the flow ratio of $\mathrm{SiH}_{4} / \mathrm{NH}_{3}$ has crucial influences on the refractivity of SiN and $\mathrm{SiH}_{4}$ flow rate and radio-frequency power have important influences on the deposition rate of $\mathrm{SiN}_{\mathrm{x}}$. According to the discussion results, the optimal technological conditions to prepare $\mathrm{SiN}_{\mathrm{x}}$ thin film are obtained, with the refractivity of $\mathrm{SiN}_{\mathrm{x}}$ of 2.2 and deposition rate of 34.79 $\mathrm{nm} / \mathrm{min}$. It is proved that PECVD can be utilized to prepare high-quality $\mathrm{SiN}_{\mathrm{x}}$ thin film with controllable refractivity and deposition rate.
\end{abstract}

\section{Introduction}

LED chips are extremely sensitive to the external environment. Thus, to improve the reliability and stability of chips, passivation film usually is covered on the surface and sides of chips. Passivation of LED chips can reduce the direct contact between chips and external atmosphere and avoid the adsorption of impurity atom to chips, which can effectively decrease the surface state density of chips [1-3], inhibit the capture of surface state to electrons, relieve current collapse effects in chips. Further, LED surface leakage current can be reduced and the reliability of chips can be effectively improved [4-6].

$\mathrm{SiN}_{\mathrm{x}}$ is the most commonly used LED passivation film at present and the common preparation methods of $\mathrm{SiN}_{\mathrm{x}}$ include low-pressure chemical vapour deposition (LPCVD), plasma-enhanced chemical vapour deposition (PECVD) and magnetron sputtering. PECVD is a major preparation method of $\mathrm{SiN}_{\mathrm{x}}$ thin film, with advantages of low deposition temperature, good technical repeatability and low film defect density.

This paper focuses on the influences of $\mathrm{SiH}_{4}$ and $\mathrm{NH}_{3}$ flow rate, temperature, radio-frequency power, pressure and other technological parameters on refractivity and deposition rate of $\mathrm{SiN}_{\mathrm{x}}$ thin film, aiming at finding reasonable technical condition combination and improving the quality of $\operatorname{SiN}_{x}$ thin film so as to satisfy the mass production requirements of LED.

\section{Experiment and the principle}

\subsection{Principle of $\mathrm{SiN}_{x}$ thin film prepared by PECVD}

PD-3800 PECVD system produced by Japan SAMCO is adopted as thin film sample deposition equipment in this experiment. Two round aluminium parallel plates are taken as top and bottom electrodes and coupled to top and bottom plates through the distribution network. Samples are resistively heated, so they own good homogeneity.

In the preparation process of $\mathrm{SiN}_{\mathrm{x}}$ by PECVD, source gases $\left(\mathrm{SiH}_{4}, \mathrm{NH}_{3}, \mathrm{~N}_{2}\right)$ flood into the reaction chamber and radio-frequency voltage is added on two plate shock. Through glow discharge, gas ionization happens on reaction gases and gases discharge under the stimulus of external electromagnetic fields forming plasma. Plasma and neutral molecules accelerated under external electric field or atomic collision generate molecules or atoms in excited state and free state ion and other active groups. Active groups react with substrate or is absorbed on the surface of substrate to obtain $\mathrm{SiN}_{\mathrm{x}}$ thin film [7].

The reaction formula can be expressed as

$$
\begin{aligned}
& 3 \mathrm{SiH}_{4} \longrightarrow \text { plasma } \longrightarrow \mathrm{SiH}_{3}^{-}+\mathrm{SiH}_{2}^{2-}+\mathrm{SiH}^{3-}+6 \mathrm{H}^{+} \\
& 2 \mathrm{NH}_{3} \longrightarrow \text { plasma } \longrightarrow \mathrm{NH}_{2}^{-}+\mathrm{NH}^{2-}+3 \mathrm{H}^{+}
\end{aligned}
$$

The total reaction formula can be expressed as

$$
3 \mathrm{SiH}_{4}+4 \mathrm{NH}_{3} \longrightarrow \text { plasma } \longrightarrow \mathrm{Si}_{3} \mathrm{H}_{4}+12 \mathrm{H}_{2} \uparrow
$$

\subsection{Experiment and test}

Usually, the main technological parameters of $\mathrm{SiN}_{\mathrm{x}}$ by PECVD are temperature of $200^{\circ} \mathrm{C}, \mathrm{NH}_{3}$ flow of 40 sccm, $\mathrm{SiH}_{4}$ flow of $400 \mathrm{sccm}$, radio-frequency power of $50 \mathrm{~W}$, furnace tube pressure of $50 \mathrm{~Pa}$ and radio-frequency time of $30 \mathrm{~min}$. Under these technological conditions, the refractivity is 1.949 and the deposition rate is 37.86 $\mathrm{nm} / \mathrm{min}$. To obtain $\mathrm{SiN}_{\mathrm{x}}$ thin film with better compactness and quality, the influences of different technological conditions on thin film thickness and refractivity are studied. The following experiments explore the influences of single technological parameter on $\mathrm{SiN}_{\mathrm{x}}$ thin film under unchanged conditions of other technological parameters.

After the sample is finished, step profiler is used to test the thickness of $\mathrm{SiN}_{\mathrm{x}}$ thin film, which is divided with deposition time to obtain the deposition rate. Ellipsometer is utilized to test the refractivity of $\mathrm{SiN}_{\mathrm{x}}$ thin film. 3 silicon slices are placed in each experiment and data from ring 3 and 5 are collected. The thickness and reflectivity of 5 points at different positions of each silicon are tested to calculate the data average of three pieces of silicon, which are listed in the table below. 


\section{Results and discussion}

\subsection{Influences of $\mathrm{SiH}_{4} / \mathrm{NH}_{3}$ on thickness and reflectivity of $\mathrm{SiN}_{\mathrm{x}}$ thin film}

With the other conditions and the total gas flow unchanged, the flow ratio of $\mathrm{SiH}_{4} / \mathrm{NH}_{3}$ varies from 2 to 25 and the proportion of $\mathrm{SiH}_{4}$ in total gas rises from $17 \%$ to $67 \%$. The test results are shown as Table 1 .

Figure 1 shows the influences of different ratios of $\mathrm{SiH}_{4} / \mathrm{NH}_{3}$ on the refractivity of $\mathrm{SiN}_{\mathrm{x}}$. With the changing ratios of $\mathrm{SiH}_{4} / \mathrm{NH}_{3}$, the refractivity of $\mathrm{SiN}_{\mathrm{x}}$ falls between 1.8 and 2.3. It can be seen from Figure 1 that the influences of different ratios of $\mathrm{SiH}_{4} / \mathrm{NH}_{3}$ on the refractivity of $\mathrm{SiN}_{\mathrm{x}}$ are significant. The higher the ratio of $\mathrm{SiH}_{4} / \mathrm{NH}_{3}$ is, the higher the refractivity of $\mathrm{SiN}_{\mathrm{x}}$ is.

Table 1 shows that under unchanged flow of $\mathrm{SiH}_{4}$ and the proportion of $\mathrm{SiH}_{4}$ in total gas, when the flow of $\mathrm{NH}_{3}$ changes, the refractivity of $\operatorname{SiN}_{x}$ increases with the increasing ratio of $\mathrm{SiH}_{4} / \mathrm{NH}_{3}$. However, the changes of $\mathrm{SiN}_{\mathrm{x}}$ thin film in deposition rate are limited. The reason for this is that with the increasing flow of $\operatorname{SiN}_{x}$, active silicon ions in plasma gas also increases, which leads to the increasing intermediate-state materials, $\mathrm{Si}\left(\mathrm{NH}_{2}\right)_{3}$, as well as thin film growth rate. Therefore, under given total gases, if the flow of $\mathrm{SiN}_{\mathrm{x}}$ remains unchanged, the deposition rate also remains unchanged.

The above experiment indicates that the flow ratio of $\mathrm{SiH}_{4} / \mathrm{NH}_{3}$ has great influences on the refractivity of $\mathrm{SiN}_{\mathrm{x}}$ thin film and has significant influences on the deposition rate of $\mathrm{SiN}_{\mathrm{x}}$ thin film.

Table 1. Influences of the flow ratio of $\mathrm{SiH}_{4} / \mathrm{NH}_{3}$ on the thickness and refractivity of $\operatorname{SiN}_{\mathrm{x}}$ thin film.

\begin{tabular}{|c|c|c|c|c|c|}
\hline $\begin{array}{c}\mathrm{SiH}_{4} \\
\text { sccm }\end{array}$ & $\begin{array}{c}\mathrm{NH}_{3} \\
\text { sccm }\end{array}$ & $\begin{array}{c}\mathrm{SiH}_{4} / \\
\mathrm{NH}_{3}\end{array}$ & $\begin{array}{c}\mathrm{SiH}_{4} / \text { total } \\
\text { gas }\end{array}$ & $\begin{array}{c}\text { Refrac } \\
\text { tivity }\end{array}$ & $\begin{array}{c}\text { Growth } \\
\text { rate } \\
\text { (nm/min) }\end{array}$ \\
\hline 100 & 50 & 2 & $17 \%$ & 1.779 & 11.04 \\
\hline 200 & 50 & 4 & $33 \%$ & 1.803 & 11.88 \\
\hline 300 & 50 & 6 & $50 \%$ & 1.839 & 27.30 \\
\hline 400 & 50 & 8 & $67 \%$ & 1.895 & 37.56 \\
\hline 400 & 40 & 10 & $67 \%$ & 1.949 & 37.86 \\
\hline 400 & 26 & 15 & $67 \%$ & 2.072 & 37.98 \\
\hline 400 & 20 & 20 & $67 \%$ & 2.180 & 35.46 \\
\hline 400 & 16 & 25 & $67 \%$ & 2.273 & 38.1 \\
\hline
\end{tabular}

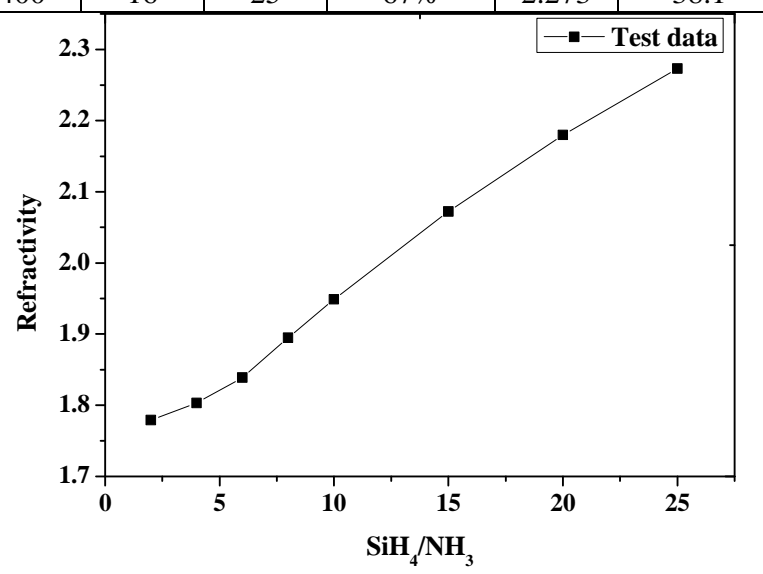

Figure 1. The influences of the flow ratio of $\mathrm{SiH}_{4} / \mathrm{NH}_{3}$ on refractivity.

\subsection{Influences of radio-frequency power on} thickness and reflectivity of $\mathrm{SiN}_{\mathrm{x}}$ thin film

With the other conditions unchanged, the radio-frequency power varies from $50 \mathrm{~W}$ to $180 \mathrm{~W}$ and the test results are shown as Table 2. It can be seen from Figure 2 that with the changes of radio-frequency power, the changes of refractivity are limited, which indicates that the influences of radio-frequency power on reflectivity are small. With then increasing radio-frequency power, the deposition rate of $\mathrm{SiN}_{\mathrm{x}}$ thin film increases. Radiofrequency power has great influences on the deposition rate of $\mathrm{SiN}_{\mathrm{x}}$, because the size of radio-frequency power directly determines the ionization degree of reaction gas in the reaction chamber. If the radio-frequency power is small, reaction gas cannot be fully ionized and its activation rate and the concentration of ion participating in the reaction are low, so the deposition rate is low. While with the increase of radio-frequency power, the activation rate is high and the concentration of ions participating in the reaction increases, so the deposition rate of $\mathrm{SiN}_{\mathrm{x}}$ thin film is high.

Table 2. Influences of radio-frequency power on refractivity and deposition rate of $\mathrm{SiN}_{\mathrm{x}}$ thin film.

\begin{tabular}{|c|c|c|}
\hline Power (W) & Refractivity & Growth rate (nm/min) \\
\hline 50 & 1.949 & 37.86 \\
\hline 80 & 1.931 & 47.46 \\
\hline 115 & 1.922 & 51.54 \\
\hline 150 & 1.926 & 54.24 \\
\hline
\end{tabular}

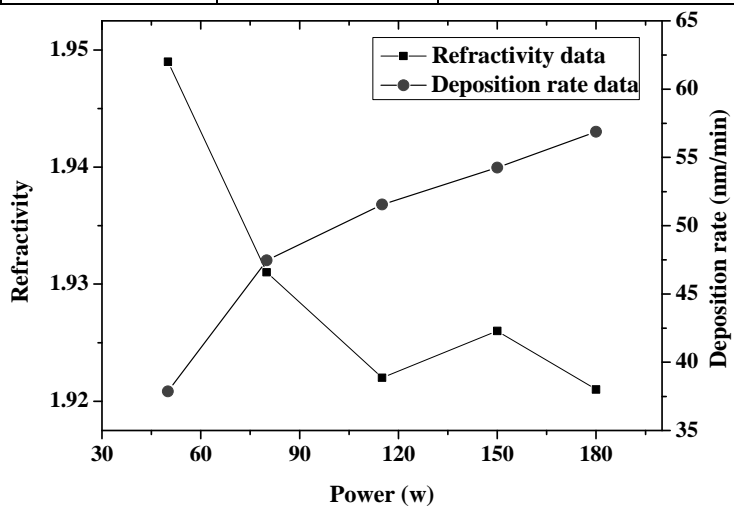

Figure 2. The influences of radio-frequency power on refractivity and deposition rate of $\mathrm{SiN}_{\mathrm{x}}$ thin film.

\subsection{Influences of chamber pressure on thickness and reflectivity of $\operatorname{SiN}_{x}$ thin film}

With the other conditions unchanged, the chamber pressure varies from $40 \mathrm{~Pa}$ to $70 \mathrm{~Pa}$ and the test results are shown as Table 3. It can be seen from Figure 3 that with the increasing chamber pressure, the refractivity of $\mathrm{SiN}_{\mathrm{x}}$ thin film decreases while the deposition rate changes little.

Table 3. Influences of chamber pressure on refractivity and deposition rate of $\mathrm{SiN}_{\mathrm{x}}$ thin film.

\begin{tabular}{|c|c|c|}
\hline Pressure $(\mathrm{Pa})$ & Refractivity & Growth rate $(\mathrm{nm} / \mathrm{min})$ \\
\hline 40 & 1.976 & 35.77 \\
\hline 50 & 1.949 & 37.86 \\
\hline 60 & 1.923 & 41.34 \\
\hline 70 & 1.910 & 43.80 \\
\hline
\end{tabular}




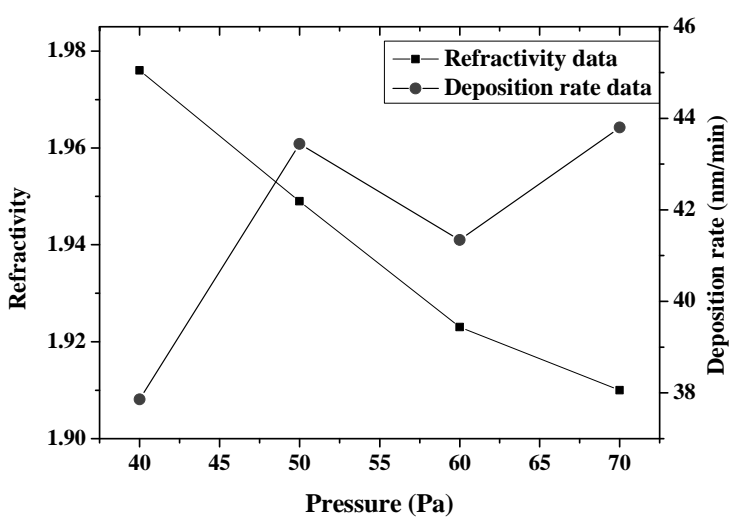

Figure 3. The influences of pressure on refractivity and deposition rate of $\mathrm{SiN}_{\mathrm{x}}$ thin film.

\subsection{Influences of temperature on thickness and reflectivity of $\operatorname{SiN}_{x}$ thin film}

With the other conditions unchanged, the temperature varies from $200{ }^{\circ} \mathrm{C}$ to $400{ }^{\circ} \mathrm{C}$ and the test results are shown as Table 4 . It can be seen from Figure 4 that with the increasing temperature, the refractivity of $\mathrm{SiN}_{\mathrm{x}}$ thin film increases while the changes of deposition rate are limited.

Table 4. Influences of temperature on refractivity and deposition rate of $\mathrm{SiN}_{\mathrm{x}}$ thin film.

\begin{tabular}{|c|c|c|}
\hline Temperature $\left({ }^{\circ} \mathrm{C}\right)$ & Refractivity & Growth rate (nm/min) \\
\hline 200 & 1.949 & 37.86 \\
\hline 325 & 1.995 & 33.90 \\
\hline 400 & 2.001 & 33.66 \\
\hline
\end{tabular}

$\mathrm{SiN}_{\mathrm{x}}$ thin film prepared in this experiment is used for LED passivation film. Refractivity is a comprehensive indicator of film component and compactness as well as an important parameter of film quality test. Thus, $\operatorname{SiN}_{x}$ thin film shall own good compactness, fast deposition rate and good repeatability. According to the influences of PECVD technological parameters on the properties of $\mathrm{SiN}_{\mathrm{x}}$ thin film above, numerous repetitive experiments are made under different technological combinations. On the basis of the comprehensive consideration of thin film quality and production efficiency, the final technological conditional combination includes temperature of $200{ }^{\circ} \mathrm{C}$, $\mathrm{NH}_{3}$ flow of $20 \mathrm{sccm}, \mathrm{SiH}_{4}$ flow of $400 \mathrm{sccm}$, radiofrequency power of $50 \mathrm{~W}$, and furnace tube pressure of $40 \mathrm{~Pa}$. Under these technological conditions, the refractivity is 2.2 and the deposition rate is $34.79 \mathrm{~nm} / \mathrm{min}$. High refractivity satisfies the passivation requirements of LED chips and the deposition rate is further controlled. Both quality and repeatability of $\mathrm{SiN}_{\mathrm{x}}$ thin film satisfy the production requirements of LED.

\section{Conclusion}

In this paper, PECVD is used to grow $\mathrm{SiN}_{\mathrm{x}}$ thin film and the influences of $\mathrm{SiH}_{4}$ and $\mathrm{NH}_{3}$ flow rate, temperature, radio-frequency power, pressure and other technological parameters on the properties of $\mathrm{SiN}_{\mathrm{x}}$ thin film are studied. The experiments find that the flow ratio of $\mathrm{SiH}_{4} / \mathrm{NH}_{3}$ has crucial influences on the refractivity of $\mathrm{SiN}_{\mathrm{x}}$; $\mathrm{SiH}_{4}$ flow rate has important influences on the deposition rate of $\mathrm{SiN}_{\mathrm{x}}$ thin film. With the changes of radio-frequency power, the changes of refractivity are limited; with the increase of radio-frequency power, the deposition rate of $\mathrm{SiN}_{\mathrm{x}}$ thin film increases. With the increase of chamber pressure, the refractivity of $\mathrm{SiN}_{\mathrm{x}}$ thin film decreases while the deposition rate changes little. With the increase of temperature, the refractivity of $\mathrm{SiN}_{\mathrm{x}}$ thin film increases while the changes of deposition rate are limited. According to the discussion results, the optimal technological condition combination to prepare $\operatorname{SiN}_{\mathrm{x}}$ thin film is obtained, with the refractivity of 2.2 and the deposition rate of $34.79 \mathrm{~nm} / \mathrm{min}$, which can satisfy the mass production requirements of LED with good compactness, fast deposition rate and good repeatability.

\section{Acknowledgment}

This work was supported by the National High Technology Research and Development Program of China (863 Program): 2015AA03A101, National Natural Science Foundation of China: U1201254 and Technology Planning Project of Guangdong Province, China: 2014B010122005.

\section{References}

[1] QIU Hong, LIU Jun-lin, WANG Li. Chenese Journal of Luminescence. Effects of SiON Passivation Layer on Reliability of GaN Based Green LED on Silicon Substrate. 32(6), 603-607(2011).

[2] Sheu J K, Lee M L, Lai W C, et al. Appl. Phys. Lett. Effect of low-temperature-grown GaN cap layer on reduced leakage current of GaN Schottky diodes. 86(5), 052103-1-3(2005).

[3] Yu Y C, Yang C C. Photonics Technology Lette. Contributions of sidewall illumination and current spreading to the light emission of InGaN-GaN light emitting diode arrays. 18(8), 983-985(2006).

[4] HUSSAM E. ELGAMEL A. Electron Devices IEEE Transactions on. High efficiency polyerystalline silicon solar cells using low temperature PECVD process. 2, 131-137 (1998).

[5] Chevtchenko S A, Reshchikov M A, Fan Q, et al. Appl. Phys. Lett. Study of $\mathrm{SiN}_{x}$ and $\mathrm{SiO}_{2}$ passivation of GaN surfaces. 101(11 ), 113709-1-6(2007)

[6] Pankove J, Berkeyheiser J, Kilpatrick S, et al. J. Electronic Materials. Passivation of GaAs surfaces. 12(2), 359-370(1983)

[7] WANG Wenjun, SUN Jianjie, ZHU Saining, ZHANG Shiquan. ELECTRONICS \& PACKAGING. Research on Silicon Nitride Films Deposited by PECVD Technology. 13(11), 4043(2013) 